\title{
Serine, glycine and one-carbon metabolism in cancer (Review)
}

\author{
SIJING PAN, MING FAN, ZHANGNAN LIU, XIA LI ${ }^{*}$ and HUIJUAN WANG* \\ Joint National Laboratory for Antibody Drug Engineering, Key Laboratory of Cellular \\ and Molecular Immunology of Henan Province, Institute of Translational Medicine, \\ School of Basic Medicine, Henan University, Kaifeng, Henan 475004, P.R. China
}

Received July 10, 2020; Accepted November 19, 2020

DOI: $10.3892 / \mathrm{ijo} .2020 .5158$

\begin{abstract}
Serine/glycine biosynthesis and one-carbon metabolism are crucial in sustaining cancer cell survival and rapid proliferation, and of high clinical relevance. Excessive activation of serine/glycine biosynthesis drives tumorigenesis and provides a single carbon unit for one-carbon metabolism. One-carbon metabolism, which is a complex cyclic metabolic network based on the chemical reaction of folate compounds, provides the necessary proteins, nucleic acids, lipids and other biological macromolecules to support tumor growth. Moreover, one-carbon metabolism also maintains the redox homeostasis of the tumor microenvironment and provides substrates for the methylation reaction. The present study reviews the role of key enzymes with tumor-promoting functions and important intermediates that are physiologically relevant to tumorigenesis in serine/glycine/one-carbon metabolism pathways. The related regulatory mechanisms of action of the key enzymes and important intermediates in tumors are also discussed. It is hoped that investigations into these pathways will provide new translational opportunities for human cancer drug development, dietary interventions, and biomarker identification.
\end{abstract}

\section{Contents}

1. Introduction

2. SSP

3. Association of the SSP with cancer cell proliferation and regulation

4. Inputs and outputs of one-carbon metabolism

Correspondence to: Dr Huijuan Wang or Dr Xia Li, Joint National Laboratory for Antibody Drug Engineering, Key Laboratory of Cellular and Molecular Immunology of Henan Province, Institute of Translational Medicine, School of Basic Medicine, Henan University, Jinming Road, Kaifeng, Henan 475004, P.R. China

E-mail: juanjuan5891@163.com

E-mail: lixia_kf@126.com

*Contributed equally

Key words: serine, glycine, one-carbon metabolism, cancer
5. Association of one-carbon metabolism with cancer cell proliferation and regulation

6. Cancer treatment and potential new opportunities

7. Conclusions

\section{Introduction}

Metabolic reprogramming is an important feature of cancer (1-3). Cancer cells maintain their survival and rapid proliferation through metabolic reprogramming, which can provide a large amount of energy and macromolecular substances required for metabolic conversion (4). Under varying stress conditions, cancer cells quickly obtain the necessary components for cell proliferation, including nucleotides, proteins and lipids, as well as important cofactors, which maintain the cancer cell redox state (5-7). The Warburg effect suggests that tumor cells produce energy in a unique manner (8). Normally, cells rely on mitochondria to oxidize carbohydrate molecules to release energy, whereas most tumor cells provide energy for themselves through glycolysis, which has a relatively low productivity $(3,9)$. In addition to upregulating glucose consumption, many tumors also increase the absorption of amino acids, such as glutamine, which is converted to $\alpha$-ketoglutarate $(\alpha-K G)$ to supplement the tricarboxylic acid (TCA) cycle $(4,10)$. Interestingly, it has been found that in proliferating cells, including cancer cells, even a high consumption of glucose and glutamine is insufficient to support the accumulation of biomass $(4,10)$. Instead, non-glutamine amino acids provide the majority of the carbon and nitrogen units (10), such as serine, which is essential for cancer cell survival (10). The glycolysis and glutaminolysis pathways provide the precursors 3-phosphoglycerate (3-PG) and glutamate, respectively, thereby fueling serine biosynthesis (11-13). The serine synthesis pathway (SSP) represents a critical turning point for glucose conversion. Serine derived from the glycolysis branch of synthesis and exogenous uptake can be converted to glycine and provide one-carbon unit for one-carbon metabolism (14). One-carbon metabolism includes the folate cycle, methionine cycle and trans-sulfuration pathway, which support porphyrin, thymidine, purine, glutathione (GSH) and S-adenosylmethionine (SAM) synthesis (15). These intermediate metabolites can be used as important precursors for the synthesis of proteins, lipids, nucleic acids and 
other cofactors, interlocking to form a complex metabolic network $(15,16)$.

The SSP and one-carbon pathway create an upregulated metabolic network in tumors and are of high clinical relevance (15,17-19). In the present review, the significance of the SSP in cancer and its related regulatory mechanisms of action are outlined, as well as the contribution that one-carbon metabolism provide for cancer metabolic reprogramming pathways. These findings may help in the development of targeted antimetabolite treatments by highlighting new translational opportunities for dietary interventions, drug development and biomarker identification.

\section{SSP}

Cancer cells generally use glycolysis to maintain their energy supply and serine biosynthesis is an important branch of glycolysis (11). 3-PG, an intermediate product of glycolysis, is a precursor of serine biosynthesis (9). Overall, $\sim 10 \%$ of 3-PG is converted into serine after a three-step enzymatic reaction (Fig. 1): In the first step, 3-PG is oxidized to 3-phosphate hydroxypyruvate by phosphoglycerate dehydrogenase (PHGDH) (18). It is then catalyzed to 3-phosphoserine and $\alpha-K G$ by phosphoserine aminotransferase (PSAT1), and finally dephosphorylated to serine by 1-3-phosphoserine phosphatase (PSPH) (18). The mutual conversion of serine and glycine can then be achieved by serine hydroxymethyl transferase (SHMT1/2) (20). It has been reported that the gene encoding PHGDH, located on chromosome 1p12, is upregulated in most types of human tumors, such as breast cancer and melanoma $(21,22)$. In addition, short hairpin RNA screening results reveal that breast cancer cell lines and melanoma cell lines require PHGDH amplification to support tumorigenesis (21-23). Similarly, high levels of PHGDH and SHMT2 have been found in a subgroup of patients with lung cancer who have a particularly poor prognosis (24). PHGDH inhibition can reduce tumor growth and differentiation of neuroendocrine prostate cancer in vivo (25). All of these studies indicate that PHGDH is very important for the proliferation and survival of tumor cells. Other studies have revealed that PSAT1 is upregulated in colorectal cancer (CRC), esophageal squamous cell carcinoma and non-small cell lung cancer, and that PSAT1 overexpression leads to a poor prognosis by enhancing cancer cell proliferation, metastasis and chemoresistance (26-28). Additionally, in patients with hepatocellular carcinoma (HCC), the expression levels of PSPH gradually increase with HCC progression and the abnormal expression of PSPH is highly correlated with patient mortality, indicating that the PSPH protein is a probable prognostic biomarker for HCC (11). Taken together, high expression levels of metabolic enzymes in the SSP may be necessary and sufficient to maintain cancer growth and oncogenic transformation.

\section{Association of the SSP with cancer cell proliferation and regulation}

Patients with malignant tumors are at high risk of malnutrition, with 40-80\% afflicted by this condition. Under nutritional deprivation, cancer cells are adept at obtaining any required energy during the opportunistic mode to support their own survival and growth, which means metabolic reprogramming (4). It has long been known that both exogenously ingested serine and endogenously synthesized serine are associated with cancer and functionally support cancer development $(12,29,30)$. As aforementioned, the high expression levels of the metabolic enzymes PHGDH, PSAT1 and PSPH in the SSP may be indispensable for maintaining cancer growth and oncogenic transformation $(21,23,25-27)$. Moreover, metabolic enzymes in the SSP are subject to transcriptional regulation by various transcription factors after stress response or oncogene activation, to cope with various types of stress, including nutritional deficiencies (11). The present review subsequently discusses the ways in which the transcriptional factors activating transcription factor 4 (ATF4) and c-MYC, as well as the oncogene $\mathrm{p} 53$, activate the SSP and perform genomic modification of the metabolic enzymes in the SSP, to assist tumor metabolic reprogramming under nutritional deficiency and/or serine deprivation $(11,31,32)$.

Activating transcription factor 4 (ATF4) is a member of the cyclic adenosine monophosphate responsive element-binding (CREB) protein family. According to previous reports, the gene encoding the CREB protein family is not only expressed in a variety of tumors, but also is a potent stress-response gene in tumors $(33,34)$. Many ATF4 target genes are involved in the maintenance of amino acids homeostasis (35-37). By regulating the adverse environment, ATF4 can protect tumor cells from nutritional stress and a series of cancer therapeutic agents (37-40). PHGDH, PSAT1 and PSPH inhibition by ATF4 small interfering RNA was first reported by Adams (41). In addition, under amino acid starvation, high expression levels of PHGDH, PSAT1 and PSPH can be induced through the general control nonderepressible 2-ATF4-dependent pathway (42). Gao et al (43) were the first to reveal that the expression levels of PSAT1 in ER-negative breast cancer were significantly upregulated. ATF4 was also found to directly enhance the expression of PSAT1 in ER-negative breast cancer, which upregulated cyclin D1 through the GSK3 $\beta / \beta$-catenin pathway, and finally promoted the proliferation of ER-negative breast cancer cells in vitro and in vivo (43). DeNicola et al (31) integrated metabolite tracing with gene expression analysis revealing that NF-E2-related factor 2 positively regulated the expression levels of PHGDH, PSAT1 and SHMT2 in SSP by targeting ATF4, which controlled the metabolic flux of glycolysis to serine, thereby supporting the production of GSH and nucleotides . Epigenetic modifiers also regulate the expression of key enzymes in the SSP (44-46). Histone H3 lysine 9 (H3K9) methyltransferase G9A is required for the transcriptional activation of key enzymes in the SSP during an active state, marked by H3K9 monomethylation, which is dependent on ATF4 (47). Coincidentally, Zhao et al (45) speculated that the H3K9 demethylase lysine demethylases 4 (KDM4) may also play a role in the transcriptional regulation of SSP. KDM4C specifically epigenetically activates the metabolic enzyme genes $\mathrm{PHGDH}$, PSAT1 and SHMT2, by removing the restrictive modification of $\mathrm{H} 3 \mathrm{~K} 9 \mathrm{me} 3$. This action requires ATF4 and interacts with ATF4 to target the metabolic enzyme genes and enhance the expression of their mRNA and protein, suggesting that KDM4C exerts a role in coordinating amino acid metabolism through a series of regulatory mechanisms (45). These studies indicate that as an upstream regulator of the SSP, targeting ATF4 is an effective 


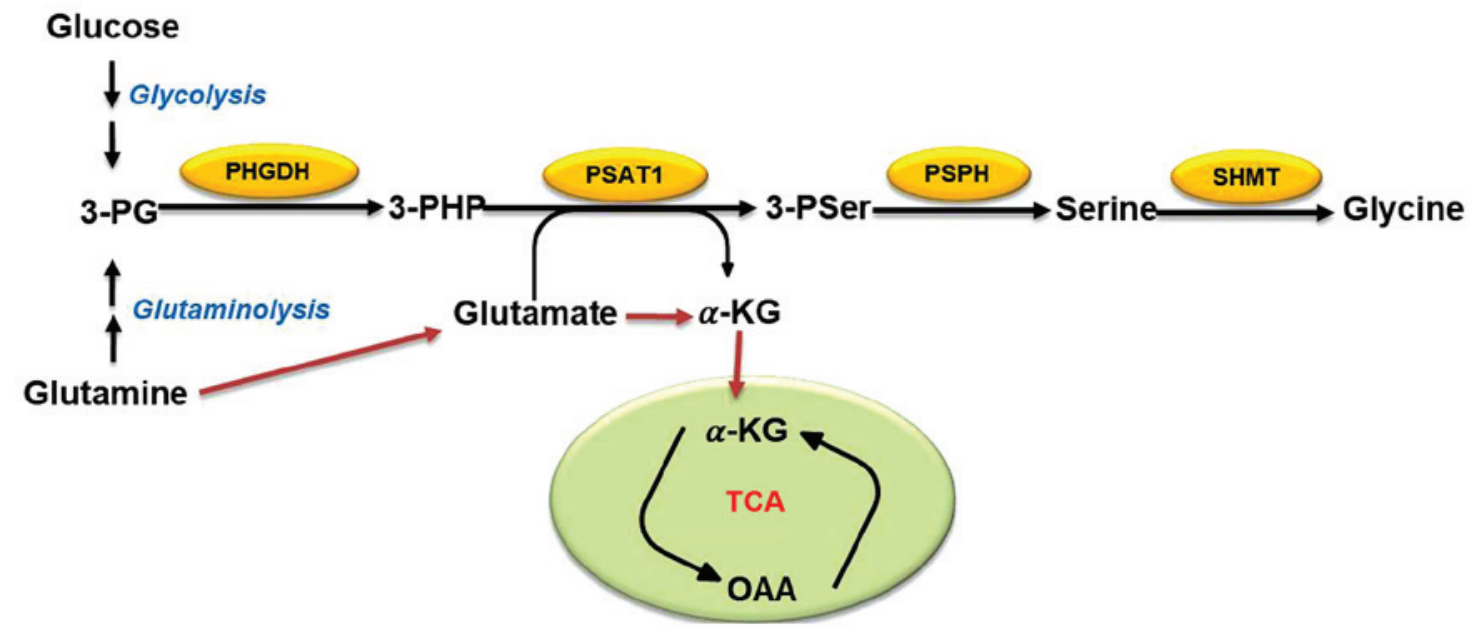

Figure 1. The Serine-glycine biosynthesis pathway. The glycolysis pathway and glutamine catabolism provide an intermediate metabolite, 3-PG, which is gradually catalyzed into serine by PHGDH, PSAT1 and PSPH. Finally, serine is converted into glycine by SHMT1/2. Yellow ovals represent metabolic enzymes. 3-PG, 3-phosphoglycerate; 3-PHP, 3-phosphate hydroxypyruvate; 3-Pser, 3-phosphoserine; $\alpha$-KG, $\alpha$-ketoglutarate; OAA, oxaloacetate; PHGDH, phosphoglycerate dehydrogenase; PSAT, phosphoserine aminotransferase; PSPH, phosphoserine phosphatase; SHMT, serine hydroxymethyltransferase; TCA, tricarboxylic acid.

mechanism for blocking the SSP in a coordinated fashion. As such, ATF4 may be a promising therapeutic target.

As an oncogene, c-Myc drives malignant progression and induces a powerful anabolic and proliferative program, resulting in the occurrence of intrinsic stress $(36,48-50)$. Of note, transcription factor c-Myc can regulate $10-15 \%$ of human genes and participate in the cell cycle as well as cellular development, apoptosis and metabolism (51-53). There is evidence that c-Myc selectively fine tunes the expression of various genes which are vital for cell growth and cancer progression (54-56). Not only does c-Myc regulate the metabolism of glucose, glutamate and nucleotides, but also it participates in SSP activation induced by nutritional starvation (11,57-59). Sun et al (11) identified the Ebox c-Myc binding site on the PHGDH, PSAT1 and PSPH loci and that knocking out c-Myc can reduce the expression of these genes. c-Myc-mediated PSPH expression and SSP activation are essential for cancer cell survival and proliferation because of their regulation of the redox levels between GSH and reactive oxygen species (ROS), nucleotide biosynthesis and cell cycle progression (11). In addition, since c-Myc activation can induce ATF4 expression by activating the integrating stress response $(36,60)$, the induction of PHGDH by c-Myc may depend on ATF4. It is worth noting that Myc transcription induces ribonucleoprotein polypyrimidine tract binding protein, heterogeneous nuclear ribonucleoprotein (hnRNP) A1 and hnRNPA2 to promote the production of pyruvate kinase M2 (PKM2) $(61,62)$. Serine is the only amino acid that can act as an allosteric activator of PKM2. Serine starvation reduces the activity of PKM2 enzymes and leads to the accumulation of upstream glycolysis intermediates, including 3-PG (63). Eventually, the tumor cells develop a higher proliferation rate under metabolic stress because of the significant increase of flux into the SSP (63-66). Overall, these studies indicate that Myc may promote the SSP by implementing the above two feedback pathways, demonstrating that the overall changes in c-Myc metabolism lead to SSP activation and cancer metastasis.
The tumor suppressor p53 has become recognized as an important regulator of cell metabolism, which can affect a series of cellular metabolic processes, such as glycolysis, oxidative phosphorylation, glutaminolysis and antioxidant reactions (67-71). p53 is also a key substance in the cell response to various forms of stress, including DNA damage, hypoxia and oncogene activation (68). Under nutritional deficiencies, p53 can protect cells by supporting metabolic adaptation. p53 helps cancer cells overcome serine starvation while retaining the cellular antioxidant capacity (72). p53-deficient cells cannot respond to serine starvation due to oxidative stress, which leads to a reduced viability of cancer cells and severely impaired proliferation (72). During serine starvation, activation of the p53-p21 axis in p53 $3^{+/+}$cells results in transient p21-dependent G1 arrest and reduction of S-phase cells, thereby inducing cell cycle arrest. This pathway can facilitate cell survival by effectively depleting serine reserves for GSH synthesis (32). As both metabolic reprogramming and the Warburg effect inhibit cancer cell death through the elimination of metabolic ROS (73), Maddocks et al (32) emphasized that p53 can coordinate cancer metabolic reprogramming under metabolic stress. Notably, p53 is frequently mutated in various types of human cancer, such as the common mutant, R248W. Such p53 mutants lose the function of wild-type p53 to clear cellular ROS, but retain the ability of wild-type p53 to bind to p21 and MDM2 (74). Increased levels of MDM2 promote the formation of MDM2 and ATF4 complexes, which can support cancer survival and proliferation by activating the SSP and inducing antioxidant responses under serine starvation (74,75). According to related reports, p73, a p53 homolog, also plays a significant role in serine biosynthesis (76). p73 transcriptionally induces glutaminase 2 (GLS-2) to facilitate the decomposition of glutamine, which drives the SSP through glutamate to help cancer cells resist metabolic stress (76). Interestingly, in human melanoma cells, p53 induced by Nutlin-3, downregulates the expression of PHGDH to repress de novo serine biosynthesis (77). Moreover, under serine deprivation, Puma and Noxa can be activated by 
ATF4-dependent Nutlin-3, which inhibits PHGDH and then further promotes apoptosis (77). These findings indicate that p53 promotes metabolic remodeling for cancer cell proliferation under serine starvation, although the specific regulatory role of p53 is dependent on the type of cancer cell.

\section{Inputs and outputs of one-carbon metabolism}

One-carbon metabolism includes a bicyclic pathway formed by the coupling of the folate cycle and the methionine cycle and the trans-sulfuration pathway $(15,16)$. Folate is a $\mathrm{B}$ vitamin which occurs naturally in many foods, and dietary supplements usually contain the synthetically produced form that is defined as folic acid. In the folate cycle (Fig. 2), folic acid is reduced twice by dihydrofolate (DHF) reductase (DHFR) and finally converted to tetrahydrofolate (THF). THF accepts the one-carbon unit from the conversion of serine to glycine to form 5, 10-methylenetetrahydrofolate (me-THF). me-THF is then either converted into 10 -formyltetrahydrofolate (F-THF) by methylenetetrahydrofolate dehydrogenase (MTHFD) $1 / 2 / 1 \mathrm{~L}$ or catalyzed by methylenetetrahydrofolate reductase (MTHFR) to 5-methyltetrahydrofolate (mTHF). mTHF can then be demethylated again and converted back to THF. The demethylation of mTHF completes the folate cycle and then starts the methionine cycle. mTHF transfers carbon units to homocysteine, which is then converted to methionine by methionine adenosine transferase. Methionine is used to generate SAM. SAM is a substrate of the methylation reaction, which when demethylated forms S-adenosyl homocysteine (SAH). The latter is then catalyzed by SAH hydrolase (SAHH) and converted into homocysteine, thus completing the entire methionine cycle (16).

One-carbon metabolism can circulate carbon units from various amino acids, generate a range of different outputs and integrate a variety of cellular nutritional statuses (Fig. 3) (15). The one-carbon unit is supplied by several sources. Serine is the main donor of the one-carbon unit when it is conversed to glycine. Alternatively, the glycine cleavage system (GCS) can also fuel one-carbon unit in cancer cell lines with high GCS activity, such as lung tumor-initiating cells and glioblastoma-derived cells (78). Recent evidence suggests that cancer cells can alter or even rely more on these sources to maintain one-carbon metabolism for cancer cell proliferation (15). Serine derived from exogenous uptake or de novo SSP synthesis can be cleaved into glycine by the methyltransferases SHMT1 (in the cytoplasm) and SHMT2 (in the mitochondria), and donate one-carbon unit (18). In this pathway, the one-carbon unit cleaved from serine is transferred to THF and then converted to me-THF $(15,16)$. This reaction can also proceed in the opposite direction, whereby the consumption of the one-carbon unit by SHMT converts glycine to serine $(79,80)$. These reactions demonstrate that the SSP metabolic enzymes have a significant impact on the production of the one-carbon unit. By depleting the availability of the one-carbon unit, serine starvation or downregulation of SSP metabolic enzymes causes the reduction of cancer cell proliferation and xenograft growth (80-82). Additionally, glycine, similarly to serine, can also be a source of the one-carbon unit through the GCS, although this reaction only occurs within the mitochondria and fuels one-carbon metabolism (83). THF accepts a methylene group via the GCS.
The resultant methylene-THF is then used in various downstream reactions which require a one-carbon unit (83). During this pathway, NADH can be also regenerated with the release of $\mathrm{CO}_{2}$ and ammonia $(83,84)$. Some studies, however, have found that although the GCS can support tumorigenesis $(68,85)$, its activity seems to be more inclined to the degradation/detoxification of glycine rather than the generation of the one-carbon unit for nucleotide synthesis $(80,85)$. The directionality of serine/glycine conversion is a significant factor for cancer cell metabolism and evidence indicates that mitochondrial SHMT2 is the main serine-glycine converting enzyme under the above circumstances by tracing NADPH with ${ }^{2} \mathrm{H}$-labeled glucose (86). Choline, a vitamin from the human diet, can be metabolized into betaine and donate one-carbon unit $(87,88)$. Moreover, one-carbon unit can also be derived from histidine and tryptophan (89). Although, these little-known pathways can theoretically contribute one-carbon unit, to the best of our knowledge, their importance for one-carbon metabolism in cancer cells has yet to be fully described.

The outputs of one-carbon metabolism include the production of ATP, NADPH and the regulation of energy balance, as well as the synthesis of biomacromolecules, such as proteins, lipids, nucleotides and substrates of methylation reactions (90-95). DNA synthesis requires nucleotides, which is a restrictive metabolic aspect of cell proliferation (19). With the methyl donor me-THF, deoxyuridine monophosphate (dUMP) can be methylated to generate deoxythymidine monophosphate (dTMP) by thymidylate synthase (TYMS), while me-THF is converted to DHF and reduced to THF by DHFR (16). In addition, purine can also be generated through the intermediate F-THF from the folate cycle (16). In the methionine cycle, not only is methionine itself necessary for protein synthesis, the SAM produced by adenylation can be used as the methyl donor for other pathways requiring methyl groups, including histone, DNA and RNA methylation; lysine and arginine methylation; polyamine synthesis; and methylation reactions that generate lipid head groups (96-99). As much as $40 \%$ of the SAM goes to phosphatidylcholine (PC) production in liver cells where the demand for PC is high, instead of through the Kennedy pathway (100). Homocysteine, the intermediate product of the methionine cycle, can produce GSH through cystathionine and then cysteine in the trans-sulfuration pathway (16).

One-carbon metabolism also plays an important role in cell redox balance. In each round of the folate cycle, a molecule of $\mathrm{NADP}^{+}$is produced during the reduction of me-THF by MTHFR (16). The adjustment of the $\mathrm{NADP}^{+} / \mathrm{NADPH}$ ratio helps to sustain the redox state (101). In addition, GSH, a tripeptide containing cysteine, glycine and glutamic acid, contributes to the maintenance of the $\mathrm{NADP}^{+} / \mathrm{NADPH}$ ratio and is the main contributor to the redox balance $(15,16)$. Therefore, cancer cells gain survival and proliferation advantages from changes in these metabolic pathways.

\section{Association of one-carbon metabolism with cancer cell proliferation and regulation}

In the context of disease prevention, diagnosis and treatment, the research and control of one-carbon metabolism is the basis of other medical and disease research $(15-17,102)$. As aforementioned, the output of one-carbon metabolism is 


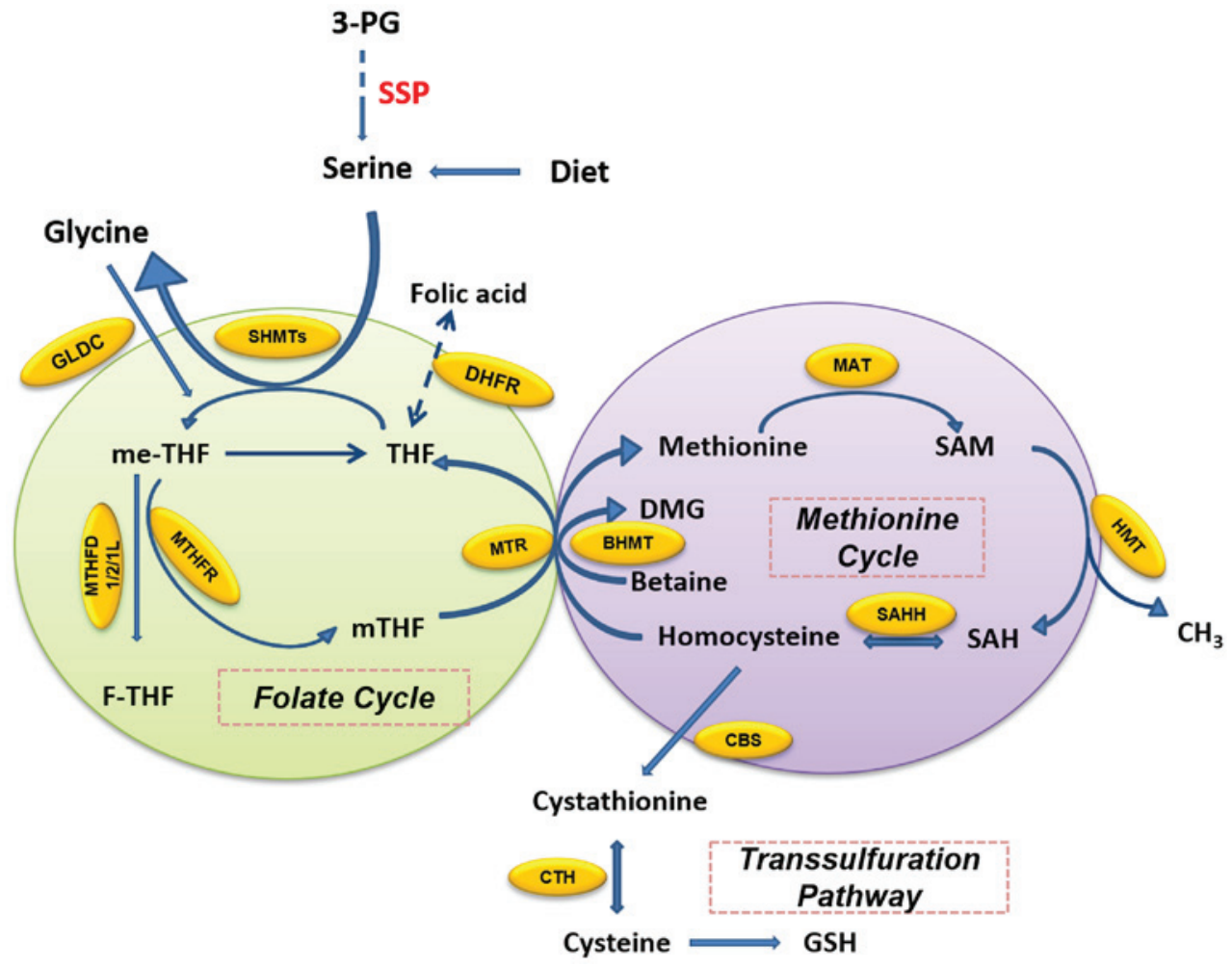

Figure 2. Overview of one-carbon metabolism around the folate cycle, methionine cycle and trans-sulfuration pathway. The folate cycle provides one carbon for the methionine cycle, as well as homocysteine, an intermediate product of the methionine cycle, which can be converted into GSH through the trans-sulfuration pathway. Yellow ovals represent metabolic enzymes. 3-PG, 3-phosphoglycerate; BHMT, betaine homocysteine methyltransferase; CBS, cystathionine $\beta$-synthase; CTH, cystathionase; DHFR, dihydrofolate reductase; DMG, dimethylglycine; F-THF, 10-formyltetrahydrofolate; GLDC, glycine dehydrogenase; GSH, glutathione; HMT, histone methyl transferase; MAT, methionine adenosyltransferase; me-THF, 5,10-methylenetetrahydrofolate; mTHF, 5-methyltetrahydrofolate; MTHFD, methylenetetrahydrofolate dehydrogenase; MTHFR, methylenetetrahydrofolate reductase; MTR, methionine synthase; SAH, S-adenosyl homocysteine; SAHH, SAH hydrolase; SAM, S-adenosylmethionine; SHMT, serine hydroxymethyltransferase; SSP, serine synthesis pathway; THF, tetrahydrofolate.

\section{Inputs}

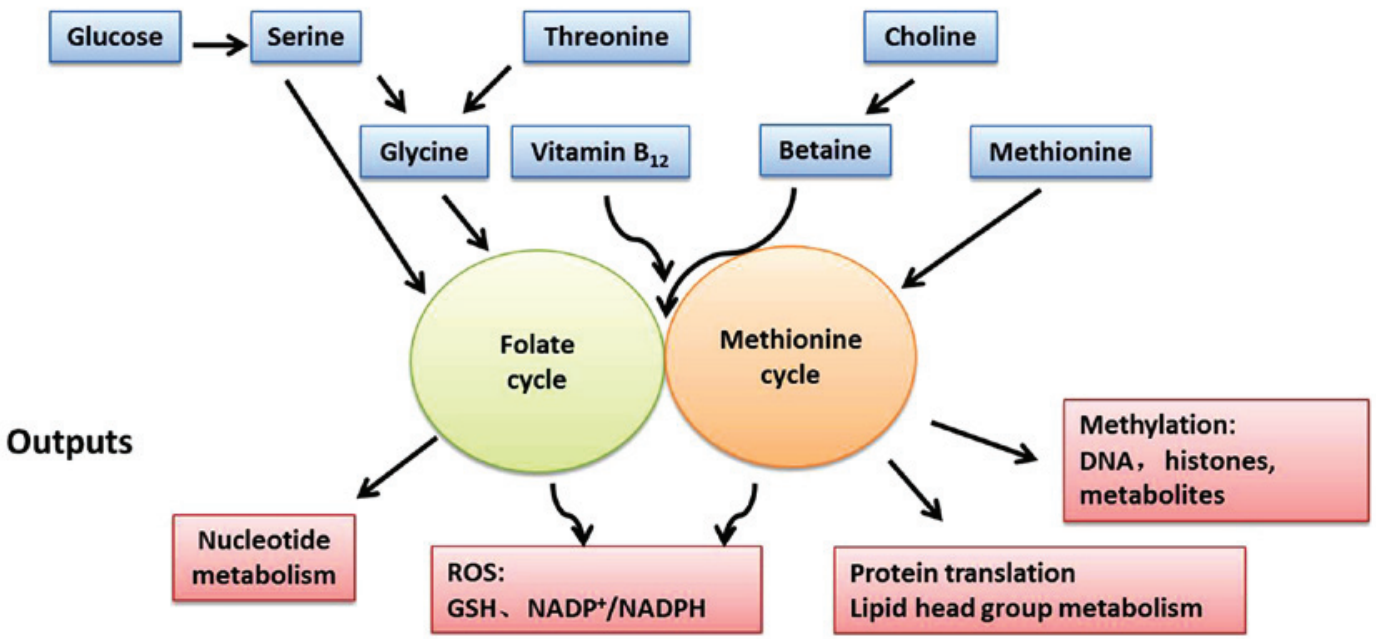

Figure 3. One-carbon metabolism integrates nutrient status and cellular functions with appropriate equilibrium in inputs and outputs. One-carbon metabolism can be viewed as a set of two modular units including the folate cycle and methionine cycle. The different nutrient sources and amino acids (serine, glycine, threonine, choline, betaine, methionine and vitamins) are inputted into the one-carbon metabolism and converted into a wide variety of outputs, such as nucleotide metabolism, redox control and post-translational modification. GSH, glutathione; ROS, reactive oxygen species.

essential for maintaining normal cell or cancer cell metabolism. For example, the methylation of DNA and histones is the most common molecular function change in cancer cells (17).
Rapidly growing cells, such as tumor cells and embryogenic cells, require the synthesis of large amounts of proteins, lipids and nucleotides to support their proliferation (94). In 
addition, the redox level in the tumor microenvironment is also key to the survival of cancer cells (91). The present review subsequently aims to discuss the main products of one-carbon metabolism and their physiological relevance, in an attempt to better understand the role of one-carbon metabolism activity in tumorigenicity and tumorigenesis.

Nucleotide synthesis. The one-carbon unit is essential for the synthesis of purine and pyrimidine nucleotides, which are necessary for the synthesis of DNA and RNA (19). De novo purine nucleotide synthesis mainly includes two stages: i) Synthesis of the important intermediate metabolite, inosine monophosphate (IMP), a common precursor of all purine nucleotides, followed by ii) the conversion of IMP into adenosine monophosphate (AMP) and guanosine monophosphate (15). IMP synthesis requires the 5-phosphate ribose provided by the pentose phosphate pathway (PPP) to combine glycine, the one-carbon unit carried by F-THF, $\mathrm{CO}_{2}$ and other substances during a series of reactions (15). Both glycine and the one-carbon unit must be generated from serine through folate metabolism in the cytoplasm or mitochondria (79). Restricting exogenous glycine or depleting the GCS cannot hinder cancer cell proliferation (80). Moreover, without serine, the ingestion of exogenous glycine also cannot support nucleotide synthesis (80). The above evidence indicates that folate metabolism plays an important role in nucleotide synthesis. Studies have revealed that inhibition of folate metabolism through serine starvation or the RNAi-mediated knockdown of SHMT2, leads to an accumulation of precursors upstream of IMP prior to incorporation with the one-carbon unit $(80,85)$. Therefore, the level of one-carbon unit required for purine nucleotide synthesis can be reduced by depletion or deprivation of serine, which then inhibits cancer cell proliferation $(80,81)$. One-carbon metabolism also provides the methyl donor for pyrimidine nucleotide synthesis. me-THF, as the methyl donor, supports the methylation reaction of dUMP to generate dTMP catalyzed by TYMS. me-THF is then converted to DHF and reduced to THF by DHFR (17). Therefore, targeting glycine dehydrogenase (GLDC), SHMT or TYMS, which promote pyrimidine synthesis, may be a potential way to suppress cancer development (24,103-105). As the key enzyme in the folate cycle, the expression of MTHFD2 is closely related to mTORC1 signaling in both normal cells and cancer cells. MTHFD2 expression is stimulated by ATF4 activated by mTORC1 independent of eukaryotic initiation factor $2 \alpha$ phosphorylation and MTHFD2 enhances F-THF production to support the synthesis of purines $(106,107)$. Interestingly, mTORC1 can also phosphorylate carbamoyl phosphate synthetase 2, aspartate transcarbamylase and dihydroorotatase with the help of its downstream target ribosomal protein, S6 kinase 1, thereby promoting pyrimidine synthesis $(108,109)$. These relationships indicate that mTORC1 can enhance the folate cycle and nucleotide synthesis to adapt to the increased RNA and DNA synthesis required for cancer cell anabolics (19).

Methylation pathway. The methylation pathway is one of the tumor metabolic reprogramming pathways and all methyltransferase reactions in mammalian cells are completely dependent on the methyl donor, SAM. The levels of SAM and its derivative
SAH can directly affect the epigenetic landscape of tumor cells by regulating the activity of key epigenetic enzymes and ultimately, determine the fate of cancer cells (110). The expression of tumor-suppressor gene promoters can be suppressed through hypermethylation, which then weakens their ability to inhibit the tumorigenic transformation of cells $(98,111,112)$. PKM2 knockdown contributes to SAM production in mouse models $(113,114)$, suggesting that PKM2 is involved in the regulation of the SAM-mediated cancer phenotype by controlling methylation. In highly lethal prostate cancer with protein kinase $\mathrm{C} \zeta(\mathrm{PKC} \lambda) / \mathrm{\iota}$ deficiency, the active mTORC1-mediated ATF4-SSP/one-carbon metabolism axis upregulates SAM synthesis (25). This approach helps to increase the plasticity of cell lineages and even gives human cancer and mouse models in vivo resistance to targeted therapy (25). In addition, the absence of serine-threonine kinase (LKB1) in Kirsten rat sarcoma 2 viral oncogene homolog (KRAS) mutant pancreatic cancer promotes tumorigenesis (115). LKB1 deletion increases the expression of SSP metabolic enzymes, which activates de novo serine biosynthesis and produces SAM through one-carbon metabolism, ultimately increasing the overall amount of DNA methylation and the levels of several DNA methyltransferases in LKB1-deficient KRAS mutant cells. This indicates that this type of SAM-dependent methylation pathway contributes to the metabolic reprogramming of tumors (115). Interestingly, it has generally been believed that the methionine cycle is mainly supported by the one-carbon unit cleaved from the serine/glycine synthesis pathway, but in fact, this pathway has very low activity in cancer cells $(116,117)$. It has been reported that the metabolism of serine and glycine can support de novo ATP synthesis and the adenosine derived from ATP can participate in the conversion of methionine to SAM (81). Therefore, the restriction of serine can also reduce the transfer of methyl units to DNA and RNA in cancer cells by reducing de novo ATP synthesis $(15,81)$.

Redox balance. NADH and NADPH are important cofactors and can provide electrons for redox reactions. These molecules can be produced by one-carbon metabolism and are essential for multiple metabolic and biosynthetic pathways (91). In the folic acid cycle, me-THF can convert to F-THF, which is catalyzed by MTHFD. NAD ${ }^{+}$or $\mathrm{NADP}^{+}$as the cofactor in this reaction can be reduced to NADH or NADPH, respectively. MTHFD2 and MTHFD2-Like (MTHFD2L) are two forms of mitochondrial MTHFD which can use both $\mathrm{NAD}^{+}$and $\mathrm{NADP}^{+}$as cofactors to generate mitochondrial NADH and NADPH $(86,118,119)$, respectively. The cytoplasmic MTHFD1 can only utilize $\mathrm{NADP}^{+}$; however, the functional correlation of the aforementioned dual-specificity remains unknown (119). During the catabolism process, the MTHFD2 reaction runs at a faster rate than the one-carbon unit required for purine synthesis (79). This enables cells to increase the production of $\mathrm{NADH}$. NADH is known to contribute to a respiratory chain that is coupled to oxidative phosphorylation, which circles back to ATP to maintain central energy metabolism (79). There is another pathway that produces mitochondrial NADPH, which occurs during the oxidation of F-THF to $\mathrm{CO}_{2}$ and THF by aldehyde dehydrogenase 1 family member L2, and provides some of the energy for proline synthesis (79). Although studies have shown that NADPH is mainly produced in 
mitochondria $(86,90,120)$, cytosolic NADPH can be generated by oxidizing me-THF by MTHFD1 (79). The synthesis of fatty acids in the cytoplasm is mainly supported by NADPH formed by the action of malic enzyme. In addition, the cytoplasmic NADPH derived from folate metabolism can also specifically support fatty acid synthesis (15). Fatty acids are necessary for the production of lipid signaling molecules and membranes, and both are essential for sustaining cancer cell proliferation (121). Serine/one-carbon metabolism also depends on the cytoplasmic NADPH/NADP ratio maintained by the activity of the oxidative PPP (oxPPP). Studies have shown that the loss of glucose 6-phosphate phosphate dehydrogenase can inhibit oxPPP, leading to high NADP and impairing folate-mediated biosynthesis by inhibiting DHFR activity with high NADP in CRC cells (91). This indicates that oxPPP is crucial for maintaining normal NADPH/NADP ratios, DHFR activity and folate metabolism. SHMT2 is a direct target gene of c-Myc (122). When MYC-transformed cells are subjected to hypoxia, SHMT2 is induced and triggers the degradation of serine to $\mathrm{CO}_{2}$ and $\mathrm{NH}_{4}^{+}$, simultaneously producing net NADPH to maintain oxidation of the tumor microenvironment (122). A study concerning human glioblastoma multiforme confirmed this was the case in this disease. SHMT2 and GLDC are highly expressed in the pseudopalisading cells around necrotic lesions (85). SHMT2 inhibits PKM2 activity and reduces oxygen consumption, which triggers a novel metabolic state, conferring a profound survival advantage to cells in tumor regions with poor vascularization (85). In addition, GSH is one of the products of the trans-sulfuration pathway and one of the most abundant metabolites in cells. It is also important for maintaining the NADPH/NADP ${ }^{+}$ratio (123). GSH has the ability to scavenge and reduce ROS, as well as maintain the appropriate NADPH/NADP ${ }^{+}$ratio, which greatly contributes to the redox balance in cells $(123,124)$.

\section{Cancer treatment and potential new opportunities}

One of the major challenges for cancer biology is to find novel and effective therapeutic targets that can be used for interventions with chemically selective pharmaceuticals in different patients. Antimetabolite drugs (antifolates) are a landmark in cancer chemotherapy and are still the most widely used drugs in medical oncology (Table I) (125-134). Among the antifolates, methotrexate and pemetrexed are effective inhibitors of DHFR, which can reduce the THF pool and prevent cell proliferation $(135,136)$. As such, they are a major class of cancer chemotherapeutic drugs and are currently used as a first-line chemotherapeutic agent in the treatment of various cancers, including acute lymphoblastic leukemia, breast cancer, bladder cancer and lymphoma $(137,138)$. Studies have found that methotrexate and pemetrexed also have the ability to bind to and inhibit human SHMT in vitro (139). There are other drugs that target the downstream pathway of the SSP/one-carbon metabolism which have been approved for clinical use, such as gemcitabine and 5-fluorouracil (5-FU) (140,141). 5-FU, a congener of uracil and a standard drug used to treat a variety of cancers, inhibits TYMS, resulting in the reduction of the methylation of dUMP to dTMP and the interruption of the folate cycle (141). 5-FU can also be converted to 5-fluorouridine, which is incorporated into ribosomal RNA (rRNA) molecules and inhibits rRNA processing, eventually leading to p53-dependent cell cycle arrest and/or apoptosis (142). Traditional antifolate chemotherapy drugs, such as methotrexate and 5-FU, have been used in clinical cancer chemotherapy to target one-carbon metabolic pathways for $\sim 70$ years (72). However, since the folate metabolism pathway is also important in normal cell proliferation, these drugs have many harmful side effects. Moreover, resistance to antifolates is also a common problem in cancer treatment (15). For these reasons, the development of new targets and new drugs is crucial.

Currently, other studies targeting the downstream of $\mathrm{SSP} /$ one-carbon metabolism are attempting to regulate the epigenetic state of the tumors and regulate the metabolic enzymes that are overactivated in the tumors $(15,72,143)$. Epigenetic reprogramming through the regulation of the methylation pathway is essential for the malignant tumor phenotype with studies suggesting that the control of methylation is possible $(144,145)$. As aforementioned, methotrexate has been widely used for cancer treatment since 1948, but it has only recently been found that methotrexate can decrease Wnt-induced intracellular lysosome activity and reduce typical Wnt signaling by inhibiting SAM levels and blocking arginine methylation (146). These findings indicate that methotrexate may be used to treat Wnt-driven malignant tumors. It has been found that the activation of SSP/one-carbon metabolic pathway genes during cancer metabolic control depends on the G9A epigenetic program (47,143), and the G9A inhibitor, BIX01294, can cause cell death by depriving serine in vivo (147), This suggests that G9A inhibition may be a therapeutic strategy for the treatment of cancer, a possibility that is contributing to the development of G9A-like drug molecules. The H3K4 demethylase jumonji AT rich interactive domain 1B (Jarid1b) (Lysine demethylase 5B/PLU-1/retinoblastoma binding protein 2-homolog 1) supports the continuous tumor growth in certain cell subsets of slow-circulating melanoma (148). These cancer cell subtypes exhibit slow DNA replication and may be resistant to chemotherapeutic agents and radiation, thereby contributing to tumor recurrence and metastasis (148). In solid cancers, histone lysine demethylase family members are associated with cancer progression. Knockdown of related genes can therefore suppress carcinogenicity and promote cell senescence $(149,150)$. Methylation donors, ornithine decarboxylation and polyamine metabolism have been widely investigated as anti-cancer therapeutic targets, with some of these drugs entering clinical trials, such as ornithine decarboxylase inhibitor; 2-difluoromethylornithine, a competitive inhibitor of SAM decarboxylase; methylglyoxal bis (guanylhydrazone); and SAM486A $(133,151)$. Targeting SSP metabolic enzymes also appears to be a promising method. PKC $\zeta$ not only inhibits the transcription of PHGDH and PSAT1, but also phosphorylates PHGDH to inhibit its catalytic activity (152). In addition, for certain PHGDH-dependent cancer cells, some small molecule inhibitors targeting PHGDH have been developed and successfully verified in vitro, which not only reduces cancer cell proliferation, but inhibits the growth of xenografts (153-156) (Table II).

Pharmacology can be used as a complementary strategy for cancers that do not upregulate the key enzymes of the SSP $(21,32,157)$. In addition to the positive correlation 
Table I. Antimetabolite drugs for the treatment of various types of cancer.

\begin{tabular}{|c|c|c|c|}
\hline Drug name & Targets & Therapeutic uses & Refs. \\
\hline Methotrexate & DHFR & Used to treat multiple cancers & $(131)$ \\
\hline Pemetrexed & DHFR, TYMS and SHMT & $\begin{array}{l}\text { Used to treat multiple cancers, especially non-small cell } \\
\text { lung carcinoma and pleural mesothelioma }\end{array}$ & $(131)$ \\
\hline Pralatrexate & DHFR & Peripheral T-cell lymphoma & $(125)$ \\
\hline Raltitrexed & DHFR and TYMS & Metastatic colorectal cancer & $(126)$ \\
\hline $5-\mathrm{FU}$ & TYMS & Used to treat multiple cancers, especially colorectal cancer & $(127)$ \\
\hline Gemcitabine & Ribonucleotide reductase & Used to treat multiple cancers, especially pancreatic cancer & $(128)$ \\
\hline Cytarabine & Ribonucleotide reductase & Acute leukemia & $(129)$ \\
\hline Azanucleotides & DNA methyltransferases & Myeloid leukemia & $(130)$ \\
\hline DMFO & Ornithine decaroboxylase & Clinical trial & $(133)$ \\
\hline SAM analogues & Histone methyltransferases & Clinical trial & $(134)$ \\
\hline MGBG and SMA486A & S-adenosyl decaroboxylase & Preclinical studies & (134) \\
\hline
\end{tabular}

5-FU, 5-fluoruoracil; DHFR, dihydrofolate reductase; TYMS, thymidylate synthase; SHMT, serine hydroxymethyltransferase; DMFO, 2-difluoromethyl orinithine; MGBG, methylglyoxal bis (guanylhydrazone); SMA486A, (E)-2-(4-carbamimidoyl-2,3-dihydro-1H-inden-1-ylidene) hydrazinecarboximidamide.

Table II. Inhibitors of PHGDH.

\begin{tabular}{|c|c|c|}
\hline Inhibitor name & Inhibitor type & Inhibition mechanism \\
\hline Indole derivative 1 & Orthosteric inhibitors & $\begin{array}{l}\text { Competitive inhibitors. Bind with the NAD }{ }^{+} \text {pocket of } \\
\text { PHGDH, and inhibit its activity }\end{array}$ \\
\hline Compound 9 (CBR-5884) & Allosteric inhibitors & $\begin{array}{l}\text { Noncompetitive inhibitors. Bind to a Cys in the non-active } \\
\text { site and disrupts its oligomeric state }\end{array}$ \\
\hline (DSF) & Allosteric inhibitors & $\begin{array}{l}\text { Noncompetitive inhibitors. Convert PHGDH tetramer into } \\
\text { either an inactive dimer to inhibit PHGDH activity }\end{array}$ \\
\hline Compound 14 (NCT-503) & Allosteric inhibitors & $\begin{array}{l}\text { Noncompetitive inhibitors. Closely bind to the active site } \\
\text { as a mutation of } \mathrm{C} 234 \text { in the protein's active site to reduce } \\
\text { the inhibitory effect of PHGDH }\end{array}$ \\
\hline $\begin{array}{l}\alpha \text {-ketothioamide } \\
\text { derivatives. }\end{array}$ & Allosteric inhibitors & $\begin{array}{l}\text { Decrease PHGDH activity and } \\
\text { selectively strain the proliferation of cancer cells with } \\
\text { elevated PHGDH expression }\end{array}$ \\
\hline PKUMDL-WQ-2101 & $\begin{array}{l}\text { Non-NAD }{ }^{+} \text {competing allosteric } \\
\text { inhibitors }\end{array}$ & $\begin{array}{l}\text { Form hydrogen-bond networks with R134, K57 and T59 } \\
\text { of site I to inhibit PHGDH activity }\end{array}$ \\
\hline PKUMDL-WQ-2201 & $\begin{array}{l}\text { Non-NAD }{ }^{+} \text {competing allosteric } \\
\text { inhibitors }\end{array}$ & $\begin{array}{l}\text { Form hydrogen-bond networks with T59, T56 and K57 of } \\
\text { site II to inhibit PHGDH activity }\end{array}$ \\
\hline Azacoccone E & $\begin{array}{l}\text { Natural compounds, allosteric } \\
\text { inhibitors }\end{array}$ & $\begin{array}{l}\text { Noncompetitive inhibitors. Fit at the allosteric site of } \\
\text { PHGDH to diminish enzyme activity. }\end{array}$ \\
\hline Iox A & Allosteric inhibitors & $\begin{array}{l}\text { Directly coordinate at the allosteric site in the back side of } \\
\text { the active site of PHGDH }\end{array}$ \\
\hline
\end{tabular}

DSF, disulfiram; Iox A, Ixocarpalactone A; PHGDH, phosphoglycerate dehydrogenase.

between high carbohydrate intake and cancer incidence (158), low glucose intake may have a negative effects on tumor growth and progression (159), making the reduction of exogenous serine intake a feasible approach. Indeed, serine and glycine starvation can successfully reduce xenograft and spontaneous tumor growth, and have been found to significantly improve survival rates in various mouse tumor models $(29,32)$. Particularly in the case of p53 deficiency, cancer cells are more sensitive to serine and glycine starvation (32). Metformin has recently been recognized as a promising drug for cancer treatment (160). Gravel et al (157) examined the anti-tumor effect of metforminin combination with serine starvation. Their results showed that biguanide does not inhibit serine synthesis and that cancer cells require 
serine to upregulate the glycolytic pathway to compensate for the reduction of oxidative phosphorylation induced by biguanide (159). Under a serine deficiency, biguanide activity is enhanced without relying on AMP-activated protein kinase; and serine deprivation and metformin exert joint antiproliferative effects by directly interfering with cancer cell metabolism. In addition, the deprivation of serine also changes the relative abundance of the metformin-induced TCA cycle metabolites (157). This points us to a new type of dietary manipulation that can enhance the efficacy of biguanides as antineoplastic agents.

Targeting folate metabolizing enzymes, such as MTHFD2, is another potential method for cancer treatment. MTHFD2, which is normally expressed only during embryonic development, provides the possibility of a disease-selective treatment target, through eliminating cancer cells while retaining healthy cells (161). Gustafsson et al (161) reported the synthesis and pre-clinical characterization of the first human MTHFD2 inhibitor, LY345899, providing a theoretical basis for the continued development of the structural framework for MTHFD2 inhibitors that can be effectively used for the treatment of various types of cancer. Recently, it has been reported that the expression of MTHFD2 and the stem-like properties can be enhanced in lung cancer cells that have acquired resistance to the targeted drug gefitinib (162). Furthermore, the overexpression of MTHFD2 makes gefitinib-sensitive lung cancer cells resistant to gefitinib. In these gefitinib-resistant cancer cells, the sensitivity to gefitinib, as well as the stem-like properties, can be restored after MTHFD2 knockdown or treatment with AICAR (162). Therefore, since cancer stem (like) cells are dependent on MTHFD2, therapies targeting MTHFD2 have been proposed as a therapeutic possibility for eradicating tumors and preventing recurrence (162). The problem with this approach; however, is that when targeting specific components of one-carbon metabolism, the tumor may reconnect with other metabolisms to compensate (163). The function of the MTHF enzyme is to convert me-THF to F-THF and mTHF for nucleotide synthesis and methionine recycling (143). The MTHFD enzyme has several forms: Cytoplasmic MTHFD1, mitochondrial MTHFD1-Like (MTHFD1L), MTHFD2 and MTHFD2L $(118,143)$. MTHFD2 is only expressed in embryos, tumors and undifferentiated tissues, while MTHFD2L is more widely expressed $(163,164)$. Cells primarily use mitochondrial enzymes for one-carbon metabolism, so if this effect is suppressed, cells can compensate by using cytoplasmic MTHFD1 (79). Cells primarily use mitochondrial enzymes for one-carbon metabolism, so if this effect is suppressed, cells can compensate by using cytoplasmic MTHFD1 (79).

\section{Conclusions}

In the past few years, researchers' interest in cancer metabolism has surged, leading to an expanding understanding of the metabolic pathways of cancer biology. Recent advances in comprehending the relationship between cancer and metabolism highlight the correlation between the SSP and one-carbon metabolism. At present; however, the molecular regulatory mechanism between SSP/one-carbon metabolism and cancer metabolism is not fully understood. To explore its therapeutic potential, it is necessary to biochemically dissect the ways in which these metabolic pathways promote cancer biology, in the hope of solving the mystery and helping to clinically overcome the worldwide problem of cancer.

\section{Acknowledgements}

Not applicable.

\section{Funding}

This study was conducted with thesupport of the National Natural Science Foundation of China (grant no. 81872023), the China Postdoctoral Science Foundation (grant no. 2018M642742) and the Henan Province Key Research and Development and Promotion Project (grant no. 202102310412).

\section{Availability of data and materials}

Not applicable.

\section{Authors' contributions}

SP, MF and ZL collected information and wrote the manuscript. HW and XL collected information and edited the manuscript. All authors read and approved the final version of this manuscript.

\section{Ethics approval and consent to participate}

Not applicable.

\section{Patient consent for publication}

Not applicable.

\section{Competing interests}

The authors declare that they have no competing interests.

\section{References}

1. Reznik E, Luna A, Aksoy BA, Liu EM, La K, Ostrovnaya I, Creighton CJ, Hakimi AA and Sander C: A Landscape of metabolic variation across tumor types. Cell Syst 6: 301-313.e3, 2018.

2. Sun L, Suo C, Li ST, Zhang H and Gao P: Metabolic reprogramming for cancer cells and their microenvironment: Beyond the Warburg Effect. Biochim Biophys Acta Rev Cancer 1870: 51-66, 2018.

3. Vaupel P, Schmidberger H and Mayer A: The Warburg effect: Essential part of metabolic reprogramming and central contributor to cancer progression. Int J Radiat Biol 95: 912-919, 2019.

4. DeBerardinis RJ and Chandel NS: Fundamentals of cancer metabolism. Sci Adv 2: e1600200, 2016.

5. Pavlova NN and Thompson CB: The emerging hallmarks of cancer metabolism. Cell Metab 23: 27-47, 2016.

6. Vander Heiden MG and DeBerardinis RJ: Understanding the intersections between metabolism and cancer biology. Cell 168: 657-669, 2017.

7. Vazquez A, Kamphorst JJ, Markert EK, Schug ZT, Tardito S and Gottlieb E: Cancer metabolism at a glance. J Cell Sci 129: 3367-3373, 2016.

8. Warburg O: On the origin of cancer cells. Science 123: 309-314, 1956. 
9. Bose $\mathrm{S}$ and Le A: Glucose metabolism in cancer. Adv Exp Med Biol 1063: 3-12, 2018

10. Hosios AM, Hecht VC, Danai LV, Johnson MO, Rathmell JC, Steinhauser ML, Manalis SR and Vander Heiden MG: Amino Acids rather than glucose account for the majority of cel mass in proliferating mammalian cells. Dev Cell 36: 540-549, 2016.

11. Sun L, Song L, Wan Q, Wu G, Li X, Wang Y, Wang J, Liu Z, Zhong X, He X, et al: cMyc-mediated activation of serine biosynthesis pathway is critical for cancer progression under nutrient deprivation conditions. Cell Res 25: 429-444, 2015.

12. Newman AC and Maddocks ODK: Serine and functional metabolites in cancer. Trends Cell Biol 27: 645-657, 2017.

13. Chen S, Xia Y, He F, Fu J, Xin Z, Deng B, He L, Zhou X and Ren W: Serine Supports IL- $1 \beta$ production in macrophages through mTOR signaling. Front Immunol 11: 1866, 2020

14. Sowers ML, Herring J, Zhang W, Tang H, Ou Y, Gu W and Zhang K: Analysis of glucose-derived amino acids involved in one-carbon and cancer metabolism by stable-isotope tracing gas chromatography mass spectrometry. Anal Biochem 566: 1-9, 2019.

15. Newman AC and Maddocks ODK: One-carbon metabolism in cancer. Br J Cancer 116: 1499-1504, 2017.

16. Lan X, Field MS and Stover PJ: Cell cycle regulation of folate-mediated one-carbon metabolism. Wiley Interdiscip Rev Syst Biol Med 10: e1426, 2018.

17. Ducker GS and Rabinowitz JD: One-carbon metabolism in health and disease. Cell Metab 25: 27-42, 2017.

18. Yang $M$ and Vousden KH: Serine and one-carbon metabolism in cancer. Nat Rev Cancer 16: 650-662, 2016.

19. Zeng JD, Wu WKK, Wang HY and Li XX: Serine and one-carbon metabolism, a bridge that links mTOR signaling and DNA methylation in cancer. Pharmacol Res 149: 104352, 2019.

20. Xia Y, Ye B, Ding J, Yu Y, Alptekin A, Thangaraju M, Prasad PD Ding ZC, Park EJ, Choi JH, et al: Metabolic reprogramming by MYCN confers dependence on the serine-glycine-one-carbon biosynthetic pathway. Cancer Res 79: 3837-3850, 2019.

21. Mattaini KR, Sullivan MR, Lau AN, Fiske BP, Bronson RT and Vander Heiden MG: Increased PHGDH expression promotes aberrant melanin accumulation. BMC Cancer 19: 723, 2019.

22. Samanta D, Park Y, Andrabi SA, Shelton LM, Gilkes DM and Semenza GL: PHGDH expression is required for mitochondrial redox homeostasis, breast cancer stem cell maintenance, and lung metastasis. Cancer Res 76: 4430-4442, 2016.

23. Sullivan MR, Mattaini KR, Dennstedt EA, Nguyen AA, Sivanand S, Reilly MF, Meeth K, Muir A, Darnell AM, Bosenberg MW, et al: Increased serine synthesis provides an advantage for tumors arising in tissues where serine levels are limiting. Cell Metab 29: 1410-1421.e4, 2019.

24. Zhang B, Zheng A, Hydbring P, Ambroise G, Ouchida AT, Goiny M, Vakifahmetoglu-Norberg $\mathrm{H}$ and Norberg E: PHGDH Defines a metabolic subtype in lung adenocarcinomas with poor prognosis. Cell Rep 19: 2289-2303, 2017.

25. Reina-Campos M, Linares JF, Duran A, Cordes T, L'Hermitte A, Badur MG, Bhangoo MS, Thorson PK, Richards A, Rooslid T, et al: Increased serine and one-carbon pathway metabolism by PKClambda/iota deficiency promotes neuroendocrine prostate cancer. Cancer Cell 35: 385-400.e9, 2019.

26. Liu B, Jia Y, Cao Y, Wu S, Jiang H, Sun X, Ma J, Yin X, Mao A and Shang M: Overexpression of phosphoserine aminotransferase 1 (PSAT1) predicts poor prognosis and associates with tumor progression in human esophageal squamous cell carcinoma. Cell Physiol Biochem 39: 395-406, 2016.

27. Jin HO, Hong SE, Kim JY, Jang SK, Kim YS, Sim JH, Oh AC, Kim H, Hong YJ, Lee JK and Park IC: Knock-down of PSAT1 enhances sensitivity of NSCLC cells to glutamine-limiting conditions. Anticancer Res 39: 6723-6730, 2019.

28. Fang Y, Liang X, Xu J and Cai X: miR-424 targets AKT3 and PSAT1 and has a tumor-suppressive role in human colorectal cancer. Cancer Manag Res 10: 6537-6547, 2018.

29. Maddocks ODK, Athineos D, Cheung EC, Lee $P$, Zhang $T$, van den Broek NJF, Mackay GM, Labuschagne CF, Gay D, Kruiswijk F, et al: Modulating the therapeutic response of tumours to dietary serine and glycine starvation. Nature 544: 372-376, 2017.

30. Mattaini KR, Sullivan MR and Vander Heiden MG: The importance of serine metabolism in cancer. J Cell Biol 214: 249-257, 2016.

31. DeNicola GM, Chen PH, Mullarky E, Sudderth JA, Hu Z, Wu D, Tang H, Xie Y, Asara JM, Huffman KE, et al: NRF2 regulates serine biosynthesis in non-small cell lung cancer. Nat Genet 47: $1475-1481,2015$
32. Maddocks OD, Berkers CR, Mason SM, Zheng L, Blyth K, Gottlieb E and Vousden KH: Serine starvation induces stress and p53-dependent metabolic remodelling in cancer cells. Nature 493: 542-546, 2013.

33. Wortel IMN, van der Meer LT, Kilberg MS and van Leeuwen FN: Surviving Stress: Modulation of ATF4-mediated stress responses in normal and malignant cells. Trends Endocrinol Metab 28: 794-806, 2017.

34. Kasai S, Yamazaki H, Tanji K, Engler MJ, Matsumiya T and Itoh K: Role of the ISR-ATF4 pathway and its cross talk with Nrf2 in mitochondrial quality control. J Clin Biochem Nutr 64: 1-12, 2019.

35. Dey S, Sayers CM, Verginadis II, Lehman SL, Cheng Y, Cerniglia GJ, Tuttle SW, Feldman MD, Zhang PJ, Fuchs SY, et al: ATF4-dependent induction of heme oxygenase 1 prevents anoikis and promotes metastasis. J Clin Invest 125 2592-2608, 2015.

36. Tameire F, Verginadis II, Leli NM, Polte C, Conn CS, Ojha R, Salas Salinas C, Chinga F, Monroy AM, Fu W, et al: ATF4 couples MYC-dependent translational activity to bioenergetic demands during tumour progression. Nat Cell Biol 21: 889-899, 2019.

37. Mesclon F, Lambert-Langlais S, Carraro V, Parry L, Hainault I, Jousse C, Maurin AC, Bruhat A, Fafournoux P and Averous J: Decreased ATF4 expression as a mechanism of acquired resistance to long-term amino acid limitation in cancer cells. Oncotarget 8: 27440-27453, 2017.

38. Mazor KM and Stipanuk MH: GCN2- and eIF2 $\alpha$-phosph orylation-independent, but ATF4-dependent, induction of CARE-containing genes in methionine-deficient cells. Amino Acids 48: 2831-2842, 2016.

39. Al-Baghdadi RJT, Nikonorova IA, Mirek ET, Wang Y, Park J, Belden WJ, Wek RC and Anthony TG: Role of activating transcription factor 4 in the hepatic response to amino acid depletion by asparaginase. Sci Rep 7: 1272, 2017.

40. Xu D, Dai W, Kutzler L, Lacko HA, Jefferson LS, Dennis MD and Kimball SR: ATF4-mediated upregulation of REDD1 and Sestrin 2 suppresses mTORC1 activity during prolonged leucine deprivation. J Nutr 150: 1022-1030, 2020.

41. Adams CM: Role of the transcription factor ATF4 in the anabolic actions of insulin and the anti-anabolic actions of glucocorticoids. J Biol Chem 282: 16744-16753, 2007.

42. Ye J, Mancuso A, Tong X, Ward PS, Fan J, Rabinowitz JD and Thompson CB: Pyruvate kinase M2 promotes de novo serine synthesis to sustain mTORC1 activity and cell proliferation. Proc Natl Acad Sci USA 109: 6904-6909, 2012.

43. Gao S, Ge A, Xu S, You Z, Ning S, Zhao Y and Pang D: PSAT1 is regulated by ATF4 and enhances cell proliferation via the GSK $3 \beta / \beta$-catenin/cyclin D1 signaling pathway in ER-negative breast cancer. J Exp Clin Cancer Res 36: 179, 2017.

44. Svoboda LK, Teh SSK, Sud S, Kerk S, Zebolsky A, Treichel S, Thomas D, Halbrook CJ, Lee HJ, Kremer D, et al: Menin regulates the serine biosynthetic pathway in Ewing sarcoma. J Pathol 245: 324-336, 2018.

45. Zhao E, Ding J, Xia Y, Liu M, Ye B, Choi JH, Yan C, Dong Z, Huang S, Zha Y, et al: KDM4C and ATF4 cooperate in transcriptional control of amino acid metabolism. Cell Rep 14: 506-519, 2016.

46. Kim SY, Hong M, Heo SH, Park S, Kwon TK, Sung YH, Oh Y, Lee S, Yi GS and Kim I: Inhibition of euchromatin histone-lysine $\mathrm{N}$-methyltransferase 2 sensitizes breast cancer cells to tumor necrosis factor-related apoptosis-inducing ligand through reactive oxygen species-mediated activating transcription factor 4-C/EBP homologous protein-death receptor 5 pathway activation. Mol Carcinog 57: 1492-1506, 2018.

47. Ding J, Li T, Wang X, Zhao E, Choi JH, Yang L, Zha Y, Dong Z, Huang S, Asara JM, et al: The histone H3 methyltransferase G9A epigenetically activates the serine-glycine synthesis pathway to sustain cancer cell survival and proliferation. Cell Metab 18: 896-907, 2013

48. Hydbring P, Castell A and Larsson LG: MYC modulation around the CDK2/p27/SKP2 axis. Genes (Basel) 8: 174, 2017.

49. Fallah Y, Brundage J, Allegakoen P and Shajahan-Haq AN: MYC-driven pathways in breast cancer subtypes. Biomolecules 7: $53,2017$.

50. Lancho O and Herranz D: The MYC Enhancer-ome: Long-range transcriptional regulation of MYC in cancer. Trends Cancer 4: 810-822, 2018

51. Stine ZE, Walton ZE, Altman BJ, Hsieh AL and Dang CV: MYC, metabolism, and cancer. Cancer Discov 5: 1024-1039, 2015 
52. Carabet LA, Rennie PS and Cherkasov A: Therapeutic inhibition of Myc in cancer. structural bases and computer-aided drug discovery approaches. Int J Mol Sci 20: 120, 2018.

53. Chen Y, Sun XX, Sears RC and Dai MS: Writing and erasing MYC ubiquitination and SUMOylation. Genes Dis 6: 359-371, 2019.

54. Walz S, Lorenzin F, Morton J, Wiese KE, von Eyss B, Herold S, RycakL,Dumay-OdelotH,Karim S, Bartkuhn M, etal: Activation and repression by oncogenic MYC shape tumour-specific gene expression profiles. Nature 511: 483-487, 2014.

55. Tesi A, de Pretis S, Furlan M, Filipuzzi M, Morelli MJ, Andronache A, Doni M, Verrecchia A, Pelizzola M, Amati B and Sabò A: An early Myc-dependent transcriptional program orchestrates cell growth during B-cell activation. EMBO Rep 20: e47987, 2019.

56. Robaina MC, Mazzoccoli L and Klumb CE: Germinal Centre B Cell Functions and Lymphomagenesis: Circuits Involving MYC and MicroRNAs. Cells 8: 1365, 2019.

57. Le A, Lane AN, Hamaker M, Bose S, Gouw A, Barbi J, Tsukamoto T, Rojas CJ, Slusher BS, Zhang H, et al: Glucose-independent glutamine metabolism via TCA cycling for proliferation and survival in B cells. Cell Metab 15: 110-121, 2012.

58. Wang LW, Shen H, Nobre L, Ersing I, Paulo JA, Trudeau S, Wang Z, Smith NA, Ma Y, Reinstadler B, et al: Epstein-barr-virus-induced one-carbon metabolism drives B cell transformation. Cell Metab 30: 539-555.e11, 2019.

59. Kauko O, O'Connor CM, Kulesskiy E, Sangodkar J, Aakula A, Izadmehr S, Yetukuri L, Yadav B, Padzik A, Laajala TD, et al: PP2A inhibition is a druggable MEK inhibitor resistance mechanism in KRAS-mutant lung cancer cells. Sci Transl Med 10: eaaq1093, 2018.

60. Pakos-Zebrucka K, Koryga I, Mnich K, Ljujic M, Samali A and Gorman AM: The integrated stress response. EMBO Rep 17: 1374-1395, 2016

61. David CJ, Chen M, Assanah M, Canoll P and Manley JL: HnRNP proteins controlled by c-Myc deregulate pyruvate kinase mRNA splicing in cancer. Nature 463: 364-368, 2010.

62. Luan W, Wang Y, Chen X, Shi Y, Wang J, Zhang J, Qian J, Li R, Tao T, Wei W, et al: PKM2 promotes glucose metabolism and cell growth in gliomas through a mechanism involving a let-7a/ c-Myc/hnRNPA1 feedback loop. Oncotarget 6: 13006-13018, 2015.

63. Chaneton B, Hillmann P, Zheng L, Martin ACL, Maddocks ODK, Chokkathukalam A, Coyle JE, Jankevics A, Holding FP, Vousden KH, et al: Serine is a natural ligand and allosteric activator of pyruvate kinase M2. Nature 491: 458-462, 2012.

64. Li AM and Ye J: The PHGDH enigma: Do cancer cells only need serine or also a redox modulator? Cancer Lett 476: 97-105, 2020.

65. Bao XR, Ong SE, Goldberger O, Peng J, Sharma R, Thompson DA Vafai SB, Cox AG, Marutani E, Ichinose F, et al: Mitochondrial dysfunction remodels one-carbon metabolism in human cells. Elife 5: e10575, 2016.

66. Mendez-Lucas A, Li X, Hu J, Che L, Song X, Jia J, Wang J, Xie C, Driscoll PC, Tschaharganeh DF, et al: Glucose catabolism in liver tumors induced by c-MYC can be sustained by various PKM1/PKM2 ratios and pyruvate kinase activities. Cancer Res 77: 4355-4364, 2017.

67. Zhang C, Liu J, Zhao Y, Yue X, Zhu Y, Wang X, Wu H, Blanco F, Li S, Bhanot G, et al: Glutaminase 2 is a novel negative regulator of small GTPase Rac1 and mediates p53 function in suppressing metastasis. Elife 5: e10727, 2016.

68. Kastenhuber ER and Lowe SW: Putting p53 in Context. Cell 170: 1062-1078, 2017

69. Wang S, Peng Z, Wang S, Yang L, Chen Y, Kong X, Song S, Pei P, Tian C, Yan $\mathrm{H}$, et al: KRAB-type zinc-finger proteins PITA and PISA specifically regulate p53-dependent glycolysis and mitochondrial respiration. Cell Res 28: 572-592, 2018.

70. Zhang X, Zhang X, Li Y, Shao Y, Xiao J, Zhu G and Li F: PAK4 regulates G6PD activity by p53 degradation involving colon cancer cell growth. Cell Death Dis 8: e2820, 2017.

71. Fritsche MK and Knopf A: The tumor suppressor p53 in mucosal melanoma of the head and neck. Genes (Basel) 8: 384, 2017.

72. Amelio I, Cutruzzola F, Antonov A, Agostini M and Melino G: Serine and glycine metabolism in cancer. Trends Biochem Sci 39: 191-198, 2014

73. Lu J, Tan M and Cai Q: The Warburg effect in tumor progression: Mitochondrial oxidative metabolism as an anti-metastasis mechanism. Cancer Lett 356: 156-164, 2015.
74. Humpton TJ, Hock AK, Maddocks ODK and Vousden KH: p53-mediated adaptation to serine starvation is retained by a common tumour-derived mutant. Cancer Metab 6: 18, 2018.

75. Riscal R, Schrepfer E, Arena G, Cissé MY, Bellvert F, Heuillet M, Rambow F, Bonneil E, Sabourdy F, Vincent C, et al: Chromatin-bound MDM2 regulates serine metabolism and redox homeostasis independently of p53. Mol Cell 62: 890-902, 2016.

76. Amelio I, Markert EK, Rufini A, Antonov AV, Sayan BS, Tucci P, Agostini M, Mineo TC, Levine AJ and Melino G: p73 regulates serine biosynthesis in cancer. Oncogene 33: 5039-5046, 2014

77. Ou Y, Wang SJ, Jiang L, Zheng B and Gu W: p53 Protein-mediated regulation of phosphoglycerate dehydrogenase (PHGDH) is crucial for the apoptotic response upon serine starvation. J Biol Chem 290: 457-466, 2015

78. Zhang WC, Shyh-Chang N, Yang H, Rai A, Umashankar S, Ma S, Soh BS, Sun LL, Tai BC, Nga ME, et al: Glycine decarboxylase activity drives non-small cell lung cancer tumor-initiating cells and tumorigenesis. Cell 148: 259-272, 2012.

79. Ducker GS, Chen L, Morscher RJ, Ghergurovich JM, Esposito M, Teng X, Kang Y and Rabinowitz JD: Reversal of cytosolic one-carbon flux compensates for loss of the mitochondrial folate pathway. Cell Metab 23: 1140-1153, 2016.

80. Labuschagne CF, van den Broek NJ, Mackay GM, Vousden KH and Maddocks OD: Serine, but not glycine, supports one-carbon metabolism and proliferation of cancer cells. Cell Rep 7: $1248-1258,2014$

81. Maddocks OD, Labuschagne CF, Adams PD and Vousden KH: Serine metabolism supports the methionine cycle and DNA/RNA Methylation through de novo ATP synthesis in cancer cells. Mo Cell 61: 210-221, 2016 .

82. Guo H, Xu J, Zheng Q, He J, Zhou W, Wang K, Huang X, Fan Q Ma J, Cheng J, et al: NRF2 SUMOylation promotes de novo serine synthesis and maintains HCC tumorigenesis. Cancer Lett 466: 39-48, 2019

83. Kikuchi G, Motokawa Y, Yoshida T and Hiraga K: Glycine cleavage system: Reaction mechanism, physiological significance, and hyperglycinemia. Proc Jpn Acad Ser B Phys Biol Sci 84: 246-263, 2008

84. Tedeschi PM, Markert EK, Gounder M, Lin H, Dvorzhinski D, Dolfi SC, Chan LL, Qiu J, DiPaola RS, Hirshfield KM, et al: Contribution of serine, folate and glycine metabolism to the ATP, NADPH and purine requirements of cancer cells. Cell Death Dis 4: e877, 2013.

85. Kim D, Fiske BP, Birsoy K, Freinkman E, Kami K, Possemato RL, Chudnovsky Y, Pacold ME, Chen WW, et al: SHMT2 drives glioma cell survival in ischaemia but imposes a dependence on glycine clearance. Nature 520: 363-367, 2015.

86. Lewis CA, Parker SJ, Fiske BP, McCloskey D, Gui DY, Green CR, Vokes NI, Feist AM, Vander Heiden MG, Metallo CM, et al: Tracing compartmentalized NADPH metabolism in the cytosol and mitochondria of mammalian cells. Mol Cell 55: 253-263, 2014.

87. Ueland PM: Choline and betaine in health and disease. J Inherit Metab Dis 34: 3-15, 2011.

88. Friso S, Udali S, De Santis D and Choi SW: One-carbon metabolism and epigenetics. Mol Aspects Med 54: 28-36, 2017.

89. Kanarek N, Keys HR, Cantor JR, Lewis CA, Chan SH, Kunchok T, Abu-Remaileh M, Freinkman E, Schweitzer LD and Sabatini DM: Histidine catabolism is a major determinant of methotrexate sensitivity. Nature 559: 632-636, 2018

90. Fan J, Ye J, Kamphorst JJ, Shlomi T, Thompson CB and Rabinowitz JD: Quantitative flux analysis reveals folate-dependent NADPH production. Nature 510: 298-302, 2014.

91. Chen L, Zhang Z, Hoshino A, Zheng HD, Morley M, Arany Z and Rabinowitz JD: NADPH production by the oxidative pentose-phosphate pathway supports folate metabolism. Nat Metab 1: 404-415, 2019.

92. Reid MA, Dai Z and Locasale JW: The impact of cellular metabolism on chromatin dynamics and epigenetics. Nat Cell Biol 19: 1298-1306, 2017

93. Morscher RJ, Ducker GS, Li SH, Mayer JA, Gitai Z, Sperl W and Rabinowitz JD: Mitochondrial translation requires folate-dependent tRNA methylation. Nature 554: 128-132, 2018.

94. Gao X, Lee K, Reid MA, Sanderson SM, Qiu C, Li S, Liu J and Locasale JW: Serine availability influences mitochondrial dynamics and function through lipid metabolism. Cell Rep 22: 3507-3520, 2018

95. Villa E, Ali ES, Sahu U and Ben-Sahra I: Cancer cells tune the signaling pathways to empower de novo synthesis of nucleotides. Cancers (Basel) 11: 688, 2019. 
96. Ulanovskaya OA, Zuhl AM and Cravatt BF: NNMT promotes epigenetic remodeling in cancer by creating a metabolic methylation sink. Nat Chem Biol 9: 300-306, 2013

97. Hughey CC, Trefts E, Bracy DP, James FD, Donahue EP and Wasserman DH: Glycine N-methyltransferase deletion in mice diverts carbon flux from gluconeogenesis to pathways that utilize excess methionine cycle intermediates. J Biol Chem 293: 11944-11954, 2018

98. Serefidou M, Venkatasubramani AV and Imhof A: The impact of one carbon metabolism on histone methylation. Front Genet 10 764, 2019.

99. Fukuoka $\mathrm{H}$ and Kubota T: One-carbon metabolism and lipid metabolism in DOHaD. Adv Exp Med Biol 1012: 3-9, 2018.

100. Walker AK: 1-Carbon cycle metabolites methylate their way to fatty liver. Trends Endocrinol Metab 28: 63-72, 2017.

101. Xiao W, Wang RS, Handy DE and Loscalzo J: NAD $(H)$ and NADP $(H)$ Redox couples and cellular energy metabolism. Antioxid Redox Signal 28: 251-272, 2018.

102. Hanley MP and Rosenberg DW: One-carbon metabolism and colorectal cancer: Potential mechanisms of chemoprevention. Curr Pharmacol Rep 1: 197-205, 2015.

103. Ser Z, Gao X, Johnson C, Mehrmohamadi M, Liu X, Li S and Locasale JW: targeting one carbon metabolism with an antimetabolite disrupts pyrimidine homeostasis and induces nucleotide overflow. Cell Rep 15: 2367-2376, 2016.

104.Pandey S, Garg P, Lee S, Choung HW, Choung YH, Choung PH and Chung JH: Nucleotide biosynthesis arrest by silencing SHMT1 function via vitamin B6-coupled vector and effects on tumor growth inhibition. Biomaterials 35 : 9332-9342, 2014

105. Tripathi SK, Gupta N, Mahato M, Gupta KC and Kumar P: Selective blocking of primary amines in branched polyethylenimine with biocompatible ligand alleviates cytotoxicity and augments gene delivery efficacy in mammalian cells. Colloids Surf B Biointerfaces 115: 79-85, 2014.

106. Ben-Sahra I, Hoxhaj G, Ricoult SJH, Asara JM and Manning BD: mTORC1 induces purine synthesis through control of the mitochondrial tetrahydrofolate cycle. Science 351: 728-733, 2016.

107. Park Y, Reyna-Neyra A, Philippe L and Thoreen CC: mTORC1 balances cellular amino acid supply with demand for protein synthesis through post-transcriptional control of ATF4. Cell Rep 19: 1083-1090, 2017.

108. Ben-Sahra I, Howell JJ, Asara JM and Manning BD: Stimulation of de novo pyrimidine synthesis by growth signaling through mTOR and S6K1. Science 339: 1323-1328, 2013.

109. Rabinovich S, Adler L, Yizhak K, Sarver A, Silberman A, Agron S, Stettner N, Sun Q, Brandis A, Helbling D, et al: Diversion of aspartate in ASS1-deficient tumours fosters de novo pyrimidine synthesis. Nature 527: 379-383, 2015.

110. Mentch SJ and Locasale JW: One-carbon metabolism and epigenetics: Understanding the specificity. Ann N Y Acad Sci 1363: 91-98, 2016.

111. Mahmoud AM and Ali MM: Methyl donor micronutrients that modify DNA methylation and cancer outcome. Nutrients 11: $608,2019$.

112. Morgan AE, Davies TJ and Mc Auley MT: The role of DNA methylation in ageing and cancer. Proc Nutr Soc 77: 412-422, 2018

113. Konno M, Koseki J, Kawamoto K, Nishida N, Matsui H, Dewi DL, Ozaki M, Noguchi Y, Mimori K, Gotoh N, et al Embryonic MicroRNA-369 controls metabolic splicing factors and urges cellular reprograming. PLoS One 10: e0132789, 2015

114. Li S, Swanson SK, Gogol M, Florens L, Washburn MP, Workman JL and Suganuma T: Serine and SAM responsive complex SESAME regulates histone modification crosstalk by sensing cellular metabolism. Mol Cell 60: 408-421, 2015.

115. Kottakis F, Nicolay BN, Roumane A, Karnik R, Gu H, Nagle JM, Boukhali M, Hayward MC, Li YY, Chen T, et al: LKB1 loss links serine metabolism to DNA methylation and tumorigenesis. Nature 539: 390-395, 2016.

116. Shlomi T, Fan J, Tang B, Kruger WD and Rabinowitz JD: Quantitation of cellular metabolic fluxes of methionine. Anal Chem 86: 1583-1591, 2014.

117. Mehrmohamadi M, Liu X, Shestov AA and Locasale JW: Characterization of the usage of the serine metabolic network in human cancer. Cell Rep 9: 1507-1519, 2014.

118. Nilsson R, Nicolaidou V and Koufaris C: Mitochondrial MTHFD isozymes display distinct expression, regulation, and association with cancer. Gene 716: 144032, 2019.
119. Shin M, Momb J and Appling DR: Human mitochondrial MTHFD2 is a dual redox cofactor-specific methylenetetrahydrofolate dehydrogenase/methenyltetrahydrofolate cyclohydrolase. Cancer Metab 5: 11, 2017.

120. Goodman RP, Calvo SE and Mootha VK: Spatiotemporal compartmentalization of hepatic NADH and NADPH metabolism. J Biol Chem 293: 7508-7516, 2018.

121. Röhrig F and Schulze A: The multifaceted roles of fatty acid synthesis in cancer. Nat Rev Cancer 16: 732-749, 2016.

122. Ye J, Fan J, Venneti S, Wan YW, Pawel BR, Zhang J, Finley LW, Lu C, Lindsten T, Cross JR, et al: Serine catabolism regulates mitochondrial redox control during hypoxia. Cancer Discov 4: 1406-1417, 2014

123. Ye C, Sutter BM, Wang Y, Kuang Z and Tu BP: A Metabolic function for phospholipid and histone methylation. Mol Cell 66 180-193.e188, 2017.

124. Rodriguez AE, Ducker GS, Billingham LK, Martinez CA, Mainolfi N, Suri V, Friedman A, Manfredi MG, Weinberg SE, Rabinowitz JD and Chandel NS: Serine metabolism supports macrophage IL-1beta Production. Cell Metab 29: 1003-1011. e1004, 2019

125. Ito Y, Makita S and Tobinai K: Development of new agents for peripheral T-cell lymphoma. Expert Opin Biol Ther 19: 197-209, 2019.

126. Wei N, Zhang B, Wang Y, He XH, Xu LC, Li GD, Wang YH, Wang GZ, Huang HZ and Li WT: Transarterial chemoembolization with raltitrexed-based or floxuridine-based chemotherapy for unresectable colorectal cancer liver metastasis. Clin Transl Oncol 21: 443-450, 2019

127. Goirand F, Lemaitre F, Launay M, Tron C, Chatelut E, Boyer JC, Bardou $\mathrm{M}$ and Schmitt A: How can we best monitor 5-FU administration to maximize benefit to risk ratio? Expert Opin Drug Metab Toxicol 14: 1303-1313,2018.

128. Adamska A, Elaskalani O, Emmanouilidi A, Kim M, Abdol Razak NB, Metharom P and Falasca M: Molecular and cellular mechanisms of chemoresistance in pancreatic cancer. Adv Biol Regul 68: 77-87, 2018.

129. Blair HA: Daunorubicin/cytarabine liposome: A review in acute myeloid leukaemia. Drugs 78: 1903-1910, 2018.

130. Diesch J,Zwick A, Garz AK, Palau A, Buschbeck M and Gotze KS A clinical-molecular update on azanucleoside-based therapy for the treatment of hematologic cancers. Clin Epigenetics 8: 71,2016.

131. Chabner BA and Roberts TG Jr: Timeline: Chemotherapy and the war on cancer. Nat Rev Cancer 5: 65-72, 2005.

132. Luengo A, Gui DY and Vander Heiden MG: Targeting metabolism for cancer therapy. Cell Chem Biol 24: 1161-1180, 2017.

133. Casero RA Jr and Marton LJ: Targeting polyamine metabolism and function in cancer and other hyperproliferative diseases. Nat Rev Drug Discov 6: 373-390, 2007

134. Rodriguez-Paredes M and Esteller M: Cancer epigenetics reaches mainstream oncology. Nat Med 17: 330-339, 2011.

135. Zheng Y, Lin TY, Lee G, Paddock MN, Momb J, Cheng Z, Li Q, Fei DL, Stein BD, Ramsamooj S, et al: Mitochondrial One-carbon pathway supports cytosolic folate integrity in cancer cells. Cell 175: 1546-1560.e1517, 2018.

136. Kucharczyk T, Krawczyk P, Powrózek T, Kowalski DM, Ramlau R, Kalinka-Warzocha E, Knetki-Wróblewska M, Winiarczyk K, Krzakowski $M$ and Milanowski J: The Effectiveness of pemetrexed monotherapy depending on polymorphisms in TS and MTHFR genes as well as clinical factors in advanced NSCLC patients. Pathol Oncol Res 22: 49-56, 2016.

137. Winter SS, Dunsmore KP, Devidas M, Wood BL, Esiashvili N, Chen Z, Eisenberg N, Briegel N, Hayashi RJ, Gastier-Foster JM, et al: Improved survival for children and young adults with t-lineage acute lymphoblastic leukemia: Results from the children's oncology group AALL0434 methotrexate randomization. J Clin Oncol 36: 2926-2934, 2018.

138. Cui Y, Chen H, Chen J, Zeng F, Zu X and Ding J: Gemcitabine/cisplatin versus methotrexate/vinblastine/doxorubicin/cisplatin for muscle-invasive bladder cancer: A systematic review and meta-analysis. Meta-Analysis 14: 1260-1265, 2018.

139. Calise SJ, Purich DL, Nguyen T, Saleem DA, Krueger C, Yin JD and Chan EK: 'Rod and ring' formation from IMP dehydrogenase is regulated through the one-carbon metabolic pathway. J Cell Sci 129: 3042-3052, 2016

140. Ross KC, Andrews AJ, Marion CD, Yen TJ and Bhattacharjee V: Identification of the serine biosynthesis pathway as a critical component of BRAF inhibitor resistance of melanoma, pancreatic, and non-small cell lung cancer cells. Mol Cancer Ther 16: 1596-1609, 2017. 
141. Longley DB, Harkin DP and Harkin DP: 5-fluorouracil: Mechanisms of action and clinical strategies. Nat Rev Cancer 3: 330-338, 2003.

142. Kawahata T, Kawahara K, Shimokawa M, Sakiyama A, Shiraishi T, Minami K, Yamamoto M, Shinsato Y, Arima K, Hamada T and Furukawa T: Involvement of ribosomal protein L11 expression in sensitivity of gastric cancer against 5-FU. Oncol Lett 19: 2258-2264, 2020.

143. Reina-Campos M, Diaz-Meco MT and Moscat J: The complexity of the serine glycine one-carbon pathway in cancer. J Cell Biol 219: e201907022, 2020.

144. Avgustinova A and Benitah SA: The epigenetics of tumour initiation: Cancer stem cells and their chromatin. Curr Opin Genet Dev 36: 8-15, 2016.

145. Kim M and Costello J: DNA methylation: An epigenetic mark of cellular memory. Exp Mol Med 49: e322, 2017.

146. Albrecht LV, Bui MH and De Robertis EM: Canonical Wnt is inhibited by targeting one-carbon metabolism through methotrexate or methionine deprivation. Proc Natl Acad Sci USA 116: 2987-2995, 2019.

147. Chen WL, Sun HP, Li DD, Wang ZH, You QD and Guo XK: G9a-An appealing antineoplastic target. Curr Cancer Drug Targets 17: 555-568, 2017.

148. Roesch A, Fukunaga-Kalabis M, Schmidt EC, Zabierowski SE, Brafford PA, Vultur A, Basu D, Gimotty P, Vogt T and Herlyn M: A temporarily distinct subpopulation of slow-cycling melanoma cells is required for continuous tumor growth. Cell 141: 583-594, 2010.

149. Kano Y, Konno M, Ohta K, Haraguchi N, Nishikawa S, Kagawa Y, Hamabe A, Hasegawa S, Ogawa H, Fukusumi T, et al: Jumonji/Aridlb (Jarid1b) protein modulates human esophageal cancer cell growth. Mol Clin Oncol 1: 753-757, 2013.

150. Konno M, Asai A, Kawamoto K, Nishida N, Satoh T, Doki Y, Mori $\mathrm{M}$ and Ishii $\mathrm{H}$ : The one-carbon metabolism pathway highlights therapeutic targets for gastrointestinal cancer (Review) Int J Oncol 50: 1057-1063, 2017.

151. Kaniskan HU, Martini ML and Jin J: Inhibitors of protein methyltransferases and demethylases. Chem Rev 118: 989-1068, 2018.

152. Ma L, Tao Y, Duran A, Llado V, Galvez A, Barger JF, Castilla EA, Chen J, Yajima T, Porollo A, et al: Control of nutrient stress-induced metabolic reprogramming by $\mathrm{PKC} \zeta$ in tumorigenesis. Cell 152: 599-611,2013.

153. Mullarky E, Lucki NC, Beheshti Zavareh R, Anglin JL, Gomes AP, Nicolay BN, Wong JC, Christen S, Takahashi H, Singh PK, et al: Identification of a small molecule inhibitor of 3-phosphoglycerate dehydrogenase to target serine biosynthesis in cancers. Proc Natl Acad Sci USA 113: 1778-1783, 2016.

154. Pacold ME, Brimacombe KR, Chan SH, Rohde JM, Lewis CA, Swier LJ, Possemato R, Chen WW, Sullivan LB, Fiske BP, et al A PHGDH inhibitor reveals coordination of serine synthesis and one-carbon unit fate. Nat Chem Biol 12: 452-458, 2016.
155. Zhao X, Fu J, Du J and Xu W: The Role of D-3-phosphoglycerate dehydrogenase in cancer. Int J Biol Sci 16: 1495-1506, 2020.

156. Ravez S, Spillier Q, Marteau R, Feron O and Frederick R: Challenges and opportunities in the development of serine synthetic pathway inhibitors for cancer therapy. J Med Chem 60 1227-1237, 2017

157. Gravel SP, Hulea L, Toban N, Birman E, Blouin MJ, Zakikhani M, Zhao Y, Topisirovic I, St-Pierre J and Pollak M: Serine deprivation enhances antineoplastic activity of biguanides. Cancer Res 74: 7521-7533, 2014

158. Fedirko V, Lukanova A, Bamia C, Trichopolou A, Trepo E, Nöthlings U, Schlesinger S, Aleksandrova K, Boffetta P, Tjønneland A, et al: Glycemic index, glycemic load, dietary carbohydrate, and dietary fiber intake and risk of liver and biliary tract cancers in Western Europeans. Ann Oncol 24 543-553, 2013.

159. Fine EJ, Segal-Isaacson CJ, Feinman RD, Herszkopf S, Romano MC, Tomuta N, Bontempo AF, Negassa A and Sparano JA: Targeting insulin inhibition as a metabolic therapy in advanced cancer: A pilot safety and feasibility dietary trial in 10 patients. Nutrition 28: 1028-1035, 2012.

160. Mallik R and Chowdhury TA: Metformin in cancer. Diabetes Res Clin Pract 143: 409-419, 2018.

161. Gustafsson R, Jemth AS, Gustafsson NM, Färnegårdh K, Loseva O, Wiita E, Bonagas N, Dahllund L, Llona-Minguez S, Häggblad M, et al: Crystal structure of the emerging cancer target MTHFD2 in complex with a substrate-based inhibitor. Cancer Res 77: 937-948, 2017.

162. Nishimura T, Nakata A, Chen X, Nishi K, Meguro-Horike M, Sasaki S, Kita K, Horike SI, Saitoh K, Kato K, et al: Cancer stem-like properties and gefitinib resistance are dependent on purine synthetic metabolism mediated by the mitochondrial enzyme MTHFD2. Oncogene 38: 2464-2481, 2019.

163. Bolusani S, Young BA, Cole NA, Tibbetts AS, Momb J, Bryant JD, Solmonson A and Appling DR: Mammalian MTHFD2L encodes a mitochondrial methylenetetrahydrofolate dehydrogenase isozyme expressed in adult tissues. J Biol Chem 286: 5166-5174, 2011

164. Nilsson R, Jain M, Madhusudhan N, Sheppard NG, Strittmatter L, Kampf C, Huang J, Asplund A and Mootha VK: Metabolic enzyme expression highlights a key role for MTHFD2 and the mitochondrial folate pathway in cancer. Nat Commun 5: 3128 , 2014.

This work is licensed under a Creative Commons Attribution-NonCommercial-NoDerivatives 4.0 International (CC BY-NC-ND 4.0) License. 